\title{
OS INSTRUMENTOS DA REFORMA URBANA E O IDEAL DE CIDADANIA As CONTRAdiçốes EM CURso
}

\author{
LUCIANA CORREA DO LAgO
}

\begin{abstract}
R E S U M O O ensaio busca confrontar o projeto de cidadania, contido no ideário da Reforma Urbana, com os rumos da politica urbana brasileira, local e nacional, direcionada para a ampliação dos direitos de acesso à cidade. A análise tem como foco as políticas de regularização e urbanização de assentamentos populares, tendo em vista o lugar central que ocupa, hoje, a ilegalidade da moradia na formulação da questão urbana brasileira e nas ações públicas dai decorrentes. Trata-se de uma avaliação dos principios das politicas em curso e de seus efeitos no campo valorativo do ideal igualitário. Parte-se da idéia de que os instrumentos legais acionados nos assentamentos, particularmente a Zeis, carregam princípios contraditórios. Questiona-se em que medida as normas e os padröes especificos instituidos nesses territórios institucionalizam duas classes de cidadãos, ou seja, duas referências de bem-estar, de direito social e de direito de propriedade; ambas legais e legitimas. Busca-se contribuir com o debate sobre as possibilidades de "convivência" entre igualdade e diferença, ou mesmo entre igualdade e liberdade, numa sociedade hierarquizada e profundamente desigual, onde a diferença é a expressão da inferioridade dos pobres.
\end{abstract}

P A L A V R A S - C H A V E Cidadania; politica urbana; habitação.

\section{INTRODUÇÃO}

... todos são iguais porque livres, isto é, ninguém está sob o poder de um outro porque todos obedecem às mesmas leis das quais todos são autores (autores diretamente, numa democracia participativa; indiretamente, numa democracia representativa). Donde o maior problema da democracia numa sociedade de classes ser o da manutenção de seus princípios - igualdade e liberdade - sob os efeitos da desigualdade real...

Marilena Chauí

Tomando como referência a definição de democracia, acima citada, busca-se nesse ensaio confrontar o projeto de cidadania, contido no ideário da Reforma Urbana, com os rumos da política urbana brasileira, local e nacional, direcionada para a ampliação dos direitos de acesso à cidade. Nesse sentido, a análise tem como foco as políticas de regularização e urbanização de assentamentos populares, tendo em vista o lugar central que ocupa, hoje, a ilegalidade da moradia na formulação da questão urbana brasileira e nas ações públicas daí decorrentes. Vale lembrar que a ilegalidade da moradia dos pobres como problema aparece, hoje, nos diferentes projetos políticos em disputa: dos mais "progressistas", em que as ilegalidades fundiária e urbanística são elementos da não-cidadania, aos mais "conservadores", como, por exemplo, a visão de cunho ambientalista, em que a ilegalidade 
1 Zona Especial de Interesse Social. A definição e o detalhamento desse instrumento encontram-se ao longo do texto.

2 Duarte apresenta um instigante mapeamento da reflexão sociológica sobre os paradoxos do projeto de "cidadanização" nas sociedades modernas (em especial das classes populares), entre eles, os impasses "entre o projeto universalista da Liberdade e da Igualdade e o respeito, preservação ou cultivo das diferenças (que não é senão um corolário do ideal libertário)" (Duarte, 1993, p.6). urbana é responsabilizada pela degradação ambiental. Entre os extremos ainda vale mencionar a visão liberal dos efeitos negativos da ilegalidade para um virtuoso dinamismo da economia (De Sotto, 2001).

Não se trata aqui de uma avaliação das políticas em curso, de seus efeitos concretos sobre o quadro de desigualdades e carências, mas sim de seus princípios e efeitos no campo valorativo do ideal igualitário. Os instrumentos legais acionados nos assentamentos, particularmente a Zeis, ${ }^{1}$ objeto desse ensaio, carregam princípios contraditórios. Questiona-se, aqui, em que medida as normas e os padrões específicos instituídos nesses territórios, com o objetivo de garantir a permanência dos moradores e os mínimos necessários para o bem-estar individual e coletivo, institucionalizam duas classes de cidadãos, ou seja, duas referências de bem-estar: de direito social e de direito de propriedade; ambas legais e legítimas, na medida em que a participação dos envolvidos no processo garante tal legitimidade. Busca-se, assim, contribuir com o debate (bastante caloroso, hoje, na Europa) sobre as possibilidades de "convivência" entre igualdade e diferença, ou mesmo entre igualdade e liberdade, numa sociedade hierarquizada e profundamente desigual, em que a diferença é a expressão da inferioridade dos pobres. ${ }^{2}$

Compartilha-se aqui a visão de que tais instrumentos representam importantes avanços no sentido do reconhecimento de uma grande parcela da população urbana como cidadãos (portadores de um conjunto de direitos privados e públicos) e de seus territórios residenciais como parte integrante da metrópole. Cabe avaliar se esse reconhecimento e os processos sociais aí envolvidos desnaturalizam ou reificam nossos valores hierárquicos. A própria noção "interesse social", utilizada na titulação da Zeis, tem ampla utilização (e possivelmente sua origem) no campo da assistência social, e mereceria uma discussão mais acurada sobre seus significados, não tendo esse trabalho tal pretensão. Vale mencionar, apenas, que a política de assistência tem como pressuposto a existência de grupos sociais incapazes de se integrar plenamente, ou seja, de aceder à cidadania. Essa "clientela" estaria fora do ideal integrativo, sem condiçōes de mudar seu estatuto social. Para Castel (1998), a "clientela" é objeto da política de inserção e não de integração.

$\mathrm{Na}$ contramão do assistencialismo, o processo de institucionalização das Zeis, desde sua origem no início dos anos 80 , está baseado no ideário integrativo, na perspectiva de transformar os moradores de tais áreas em cidadãos. A intenção era, e continua sendo, a de através desse instrumento colocar dentro do "mapa oficial", com condições de vida dignas, áreas e pessoas até então excluídas. O projeto da Reforma Urbana, portanto, não se esgota na busca pelo reconhecimento dos assentamentos como objeto da política urbana. Não esqueçamos que as favelas no Rio de Janeiro vêm sofrendo intervenções por parte do Estado, há mais de cinqüenta anos, através de políticas sociais e urbanas de diferentes matizes ideológicos. A questão central de um projeto democrático de cidade é garantir aos moradores dessas áreas igual condição de disputa por investimentos públicos. A conquista da cidadania, portanto, é a conquista do reconhecimento desses moradores como sujeitos políticos, que reivindicam e criam novos direitos. Não se trata, portanto, de clientela. 

L U
C I A N A
C O R R $\mathrm{R} \quad \mathrm{A}$
D O
L A G O

\section{A REGULARIZAÇÃO FUNDIÁRIA E URBANÍSTICA COMO AMPLIAÇÃO DA CIDADANIA: AS ZEIS}

Como zonas urbanas específicas, as Zeis são criadas no sentido de interferir no zoneamento das cidades, incorporando territórios que até então estavam fora das normas estabelecidas. As especificidades não se restringem às distintas ilegalidades presentes nessas áreas, abrangendo também a caracterização social dos moradores.

As Zeis são zonas urbanas específicas, que podem conter áreas públicas ou particulares ocupadas por população de baixa renda, onde há interesse público de promover a urbanização e/ou a regularização jurídica da posse da terra, para salvaguardar o direito à moradia. (Instituto Pólis, 2002, p.92.)

O zoneamento, expressão maior do urbanismo racionalista, é o principal instrumento legal de controle e ordenamento da produção e da apropriação do espaço construído, representando o interesse "difuso" (leia-se "de todos") por uma boa qualidade de vida na cidade. Como as normas legais em geral, o zoneamento fala em nome da Razão, traduzindo, em um conjunto de parâmetros, um ideal de bem-estar urbano. Vale destacar que esse ideal contém, ao mesmo tempo, princípios restritivos em relação ao direito de propriedade e princípios hierárquicos que institucionalizam as diferenças inter e intraclasses, através de zonas residenciais com padrões mínimos distintos.

O ideário da Reforma Urbana introduz mais um componente à critica ao urbanismo racionalista, isto é, ao seu princípio excludente, impeditivo da inserção legal dos moradores de assentamentos populares. ${ }^{3}$ Assim, a proposta de flexibilização da legislação urbana, através das Zeis, teria a função de aproximar a cidade ideal da real, adequando a norma à realidade. A flexibilização, nesse caso, põe em questão a legitimidade dos padrões de bem-estar socialmente aceitos e instituídos em nome de "todos". ${ }^{4}$ Voltarei a esse ponto, mais adiante, relacionando-o à politização das normas legais.

Embora tenha ganhado fama e se difundido a partir da Constituição de 1988, a institucionalização de zonas especiais, com o objetivo de integrar à cidade os assentamentos de baixa renda, remonta ao início dos anos 80, com iniciativas em Recife e Belo Horizonte. Em ambas as cidades, a presença da Igreja católica em açôes comunitárias nas favelas foi fator decisivo para esse pioneirismo em relação às normas legais. ${ }^{5} \mathrm{O}$ balanço dos resultados alcançados, nesses vinte anos, em relação ao projeto das Zeis pode ser agrupado em duas ordens de questôes: (i) o reconhecimento legal desses territórios como "zonas" da cidade; e (ii) as condições da moradia, no que se refere ao padrão de habitabilidade e à relação de propriedade. As avaliações já feitas apontam importantes avanços no sentido da legitimação e da institucionalização dos assentamentos populares como parte da cidade, criando, inclusive, reações por parte de empresas imobiliárias. $\mathrm{O}$ alto percentual de favelas transformadas em Zeis, ${ }^{6}$ não só em Recife e Belo Horizonte, evidenciam esses avanços (Alfonsín, 1997).

São inegáveis os resultados alcançados a partir do Prezeis para as comunidades de baixa renda: a possibilidade da população de baixa renda permanecer em suas comunidades, inclusive em áreas centrais, próximas a localidades com disponibilidade de serviços e equipamentos urbanos; o reconhecimento institucional do direito à participação de representantes populares na formulação e acompanhamento de políticas urbanas; a consolidação da mudança
3 Os projetos originais de diferentes cidades planejadas no Brasil evidenciam claramente a exclusão dos trabaIhadores sem qualificação, responsáveis pela construção das cidades. Os planos de Volta Redonda, Belo Horizonte, Brasília e Carajás, por exemplo, não previam uma "zona residencial" para esses trabalhadores, que foram se alojar fora das fronteiras legais das cidades (Piquet, 1998)

4 A proposta de "flexibilização" da lei está presente, hoje, em ideários politicamente opostos. Para o projeto de cidade de cunho "neolibe ral", a legislação urbana racionalista é uma barreira à gestão empreendedora, que busca uma permanente adequação do espaço da cidade às novas possibilidades de investimento.

5 Em Recife, foram criados por Decreto de 1980, 26 Áreas Especiais, tendo em vista a implantação do Promorar (programa federal de erradicação de sub-habitação). Foram elaborados projetos de urbanização para três favelas (marcos da resistência popular contra a remoção), com parâmetros urbanísticos especiais, entre eles a proibição de "remembramentos" como forma de impedir a ação dos empreendedores imobiliários. Em 1987, é sancionada a Lei do Prezeis, "prevendo um conjunto de regras, procedimentos e mecanismos para o reconhecimento de outras áreas faveladas como Zeis, para viabilizar a regularização urbanística e fundiária dos assentamentos e para efetivar um sistema de gestão participativa" (Miranda \& Moraes, 2003). Em Belo Horizonte, foi criado, pela lei municipal de 1983, o Profavela, que definia um zoneamento específico para as favelas existentes, para fins de urbanização e regularização (Alfonsín, 1997).

6 Em Recife, dos 421 as sentamentos, 252 compõem as 66 Zeis, que ocupam $85 \%$ das áreas de favelas.(Miranda \& Moraes, 2003). 
nos padrões de intervenção urbanística daqueles assentamentos. Contudo, as expectativas em relação à transformação das condiçôes de vida da população das Zeis foram, relativamente, frustradas. (Miranda \& Moraes, 2003.)

A citação acima aponta os limites da Zeis como instrumento redistributivo, ou seja, a sua capacidade limitada de redirecionar os investimentos públicos prioritariamente para as áreas especiais de interesse social. No caso de Recife, em vinte anos, apenas duas Zeis tiveram a urbanização concluída (Miranda \& Moraes, 2003). Em Belo Horizonte, a desvinculação entre a urbanização e a regularização fundiária possibilitou a titulação de lotes sem as condições "mínimas" de bem-estar (Alfonsín, 1997). Quanto à regularização fundiária, os avanços mais significativos ficaram restritos aos assentamentos em terras públicas, onde os instrumentos de Concessão de Direito Real de Uso e de Doação vêm possibilitando a titulação plena ou de direito de uso da propriedade. Em relação à titulação das posses em terras privadas, pouco foi alcançado até agora. Inúmeras barreiras, de ordem política e administrativa, impedem os encaminhamentos e/ou a conclusão dos processos de titulação através dos instrumentos da Usucapião Urbana e de Desapropriação. Mais adiante, esses instrumentos serão problematizados à luz do projeto de democratização da cidade.

A Zeis não se limita a uma função integrativa de inserir no "mapa" territórios e pessoas até então excluídos, garantindo-lhes condições mínimas de bem-estar no lugar da moradia. A Zeis pode ser um poderoso instrumento de controle e ordenamento do uso do solo urbano, interferindo na dinâmica redistributiva do mercado imobiliário. As experiências já acumuladas mostram que a ação regulatória, nesse caso, carrega intenções muito distintas. A primeira seria garantir a finalidade da moradia social através da "proteção" da área diante da especulação.

7 Porto Alegre também instituiu um tipo de Zeis, a Aeis, específica para vazios urbanos destinados a programas habitacionais.
As Zeis gravam a área do assentamento regularizado como de interesse social, ou seja, a destinação do terreno, independentemente de quem esteja morando ali, é a habitação de interesse social, o que já induz à diminuição da vantagem da especulação imobiliária nessas áreas, já que o mecanismo reduz o valor do terreno. (Instituto Pólis, 2003, p.149).

Uma segunda intenção, que não exclui a primeira, seria a de intervir no mercado de terras da cidade, "desvalorizando" áreas vazias, por meio do gravame da Zeis. Nesse caso, a experiência de Diadema merece atenção. Na Lei que disciplina o zoneamento e o uso e ocupação do solo, foram instituídos dois tipos de Zeis: ${ }^{7}$ as que são gravadas sobre áreas vazias e as que compreendem "terrenos ocupados por favelas, ou assentamentos habitacionais assemelhados, destinados a programas de reurbanização, regularização jurídica da posse da terra ou empreendimentos habitacionais de interesse social" (Alfonsín, 1997, p.101). O relevante é que está definida na Lei a destinação dessas áreas vazias: Empreendimentos Habitacionais de Interesse Social, o que evidencia uma restrição ao direito de propriedade, por uma caracterização social legalmente atribuída.

Ainda no sentido de regular o mercado imobiliário, outro mecanismo que vem sendo utilizado através das Zeis é o estabelecimento de limites máximos quanto às dimensões dos lotes conjugado ao impedimento do remembramento. Até agora, o uso desses mecanismos estão restritos às favelas, mas poderiam ser acionados para outras áreas das cidades, com boa infra-estrutura. Vale mencionar a reação, em Recife, dos empreendedores imobiliários em relação ao limite da dimensão dos lotes, reivindicando maior "flexibiliza- 
ção" das normas (Miranda \& Moraes, 2003). Estaríamos diante de uma curiosa sobreposição de "flexibilizaçôes": uma que reduz e congela os "mínimos" instituídos na legislação urbana em vigor para atender necessidades sociais especiais, congelando-os; e outra que suspenderia o congelamento. O que importa destacar aqui é a abrangência desse instrumento para além dos assentamentos populares, podendo interferir diretamente nos processos e conflitos produtores das desigualdades urbanas.

\section{OS PRINCÍPIOS DO DIREITO À TERRA: A PROPRIEDADE, O USO E A VALORIZAÇÃo}

Como já visto, são inúmeras as barreiras jurídicas, administrativas e políticas para a efetivação de uma regularização fundiária que constranja o direito de propriedade da terra. O principal avanço foi tornar visível o conflito de interesses e as contradiçōes e "brechas" nas Leis. O peculiar nesse conflito é que o ideário democrático não coloca em questão o direito de propriedade como valor, na medida em que busca transformar os moradores dos assentamentos em proprietários, plenos ou não. O que ele busca regular é o direito do proprietário auferir renda da terra sob seu domínio. Os parâmetros urbanísticos instituídos nas Zeis como forma de controle da especulação e valorização imobiliária exemplificam esse princípio.

O importante a ressaltar é a centralidade do direito de propriedade fundiária para a ampliação do exercício da cidadania. ${ }^{8}$ A propriedade da terra, no Brasil, é base e condição para o acesso a uma série de outros direitos (à justiça, ao crédito, ao financiamento imobiliário etc.) e tem sido, historicamente, um dos principais mecanismos reprodutores da estrutura hierárquica nas cidades brasileiras. Contraditoriamente, a ampliação dos direitos sociais passa, necessariamente, pela maior difusão dos direitos civis, entre eles o da propriedade. As mudanças nas fronteiras entre o público e o privado em nossas cidades, com a redução do primeiro, estão também condicionadas à difusão desses direitos. ${ }^{9} \mathrm{~A}$ experiência e a valorização do espaço público são realizadas por indivíduos conscientes de seus direitos (e deveres).

Entremos, então, no argumento central desse ensaio sobre as contradições presentes no ideário democrático relativas à regularização fundiária. Um primeiro ponto refere-se aos instrumentos mais recorrentes para esse fim.

- Concessão do Direito Real de Uso (CDRU), para posse de terras públicas, previsto em lei desde 1967, pelo Decreto Lei 271. Tal concessão se dá através de um contrato por tempo determinado, renovável e contendo destinação especificada, não havendo a possibilidade de transferência da propriedade para o outorgado. No caso de Diadema o período do contrato é de noventa anos.

- Usucapião Urbana, para posse de terras privadas. Garante a aquisição do direito real em relação à área privada sobre a qual se tem a posse durante cinco anos contínuos para fins de moradia, em lote não superior a 250m2 (Alfonsín, 1997).

Em que medida o contrato de "concessão real de uso", em contraposição ao direito pleno da propriedade, institui uma outra classe de cidadãos? É possível construir socialmente uma equivalência entre o valor da concessão de uso e o atribuído à propriedade plena? A experiência das Prezeis evidencia as dificuldades da CDRU ser aceita entre os mo-
8 Essa centralidade, muitas vezes, não é percebida como tal pelos residentes em assentamentos irregulares. Pesquisas realizadas por mim com moradores de favelas no Rio de Janeiro mostram que, nas listas de reivindicações, a titularidade da terra não é prioridade, ficando atrás da urbanização, dos equipamentos coletivos e da segurança. 0 afastamento da ameaça de remoção e, portanto, a crença no direito de uso, explicam esse fenômeno.

9 Num seminário sobre regularização urbanística, promovido pela Fundação Bento Rubião em 2004, no Rio de Janeiro, uma liderança comunitária de favela apontou a relação existente entre a expansão territorial do tráfico de drogas nas favelas e a não-titularidade da propriedade. Segundo essa lideranca, o poder do tráfico de expulsar moradores de suas casas e ocupá-las como estratégia de controle da área é fortalecido pela impossibilidade desses moradores reclamarem judicialmente seus direitos. 
radores das Zeis, "por não implicar na aquisição de direitos equivalentes aos da transferência da propriedade” (Miranda \& Moraes, 2003). O valor simbólico dos dois estatutos jurídicos está atrelado a condições objetivas diferenciadas. A desobediência das cláusulas do contrato de concessão, como por exemplo a destinação residencial do lote, pode levar, no limite, à perda do direito de uso. No caso da propriedade, poderiam se aplicadas multas e sanções. É de extrema importância a equivalência dos estatutos legais acionados nas políticas de regularização fundiária, se o objetivo for não apenas buscar restringir o direito de propriedade para democratizar o acesso à terra e aos serviços urbanos, mas legitimar essa restrição na sociedade, em geral, e no judiciário e cartórios, em particular.

Outro ponto que merece atenção diz respeito à regulação do mercado imobiliário nas Zeis, impedindo ou inibindo a venda do imóvel pelos moradores recém-legalizados. Como já assinalado, o pressuposto é de que a valorização imobiliária provocada pela regularização pode expulsar os moradores socialmente mais vulneráveis. Ou seja, esses moradores, sem uma "proteção" legal, serão expulsos pelo mercado e produzirão novas ilegalidades em outros lugares. A forma mais democrática de "proteção" seria o próprio gravame da Zeis, com normas especiais de uso do solo (lote máximo, coeficiente de edificação etc.), inibidoras do interesse dos empreendedores imobiliários por essas áreas. Tais mecanismos seriam mais efetivos para garantir a permanência dos moradores beneficiários do que a proibição da transferência do imóvel (Instituto Pólis, 2003).

Ao promoverem programas de regularização, cabe aos gestores públicos reconhecer sim os processos de mobilidade social e práticas decorrentes do exercício das liberdades individuais dos ocupantes, porém de maneira tal que se garanta que as áreas urbanas que sofrem a intervenção publica - com enorme investimento de dinheiro público - sejam reservadas para finalidade de moradia social. O instrumento das Zeis - Zonas Especiais de Interesse Social tem se mostrado muito eficaz nesse sentido, e deve ser combinado com normas urbanísticas que reconheçam as especificidades das áreas a serem regularizadas e com processos de gestão democrática. Se um dia as desigualdades macroeconômicas diminuírem no país, talvez essa proteção jurídico-urbanística não seja mais necessária. (Alfonsín \& Fernandes, 2004, p.3.)

100 caderno "Regularização Fundiária Sustentável", produzido pela Secretaria Nacional de Programas Urbanos, desenvolve bem esse argumento, apontando a necessária articulação entre as ações "curativas" (de regularização) e "preventivas" (de controle público sobre o mercado imobiliário) e a ampliação da oferta de terra urbanizada para a população de baixa renda. Cf. Ministério das Cidades, "Planejamento territorial urbano e política fundiária", Cadernos MCidades, n.3, 2004.
A idéia de uma cidadania "tutelada" ganha corpo através das propostas de "proteção" dos moradores de áreas regularizadas contra os especuladores e nos remete à distinção, apresentada por Castel (1998), entre políticas de inserção e de integração. Esses moradores estariam inseridos na cidade, na medida em que suas áreas de residência passam a ser legalmente reconhecidas, mas não integrados na sociedade. Para tanto, precisariam ser reconhecidos socialmente como iguais, como portadores dos mesmos direitos, no caso, os urbanos.

No entanto, os mecanismos de "proteção", ou seja, de regulação da valorização da terra, merecem uma análise mais abrangente, que dê conta da complexidade dos processos em curso. Pode-se utilizar os mesmos mecanismos de "proteção" dos pobres para o controle das ações especulativas na cidade como um todo. O desafio é ampliar as restrições ao direito de propriedade para além das favelas (Zeis), ou seja, para os processos que produzem e reproduzem as desigualdades de acesso à terra. ${ }^{10} \mathrm{~A}$ aplicação das Zeis em áreas vazias com infra-estrutura básica, a discussão e formulação de novos princípios e parâmetros para a Lei de Zoneamento das cidades, entre outras ações, podem caminhar nessa direção. 


\section{A REgularizAÇÃo COMO UM CAMPO DA LUTA POLÍTICA}

Um dos desafios para se levar adiante um projeto efetivo de democratização do acesso à cidade é tornar visíveis, para a sociedade, as contradições e paradoxos dos princípios que orientam o conjunto das açôes políticas. Os programas de regularização constituem um campo fértil para a reflexão e possível superação, ao longo da luta política, de algumas dessas contradiçôes. É nesse sentido que devemos nos indagar sobre as possibilidades e os limites da convivência entre os princípios de "igualdade" e de respeito às "diferenças". No caso das Zeis, encontramos uma sobreposição de significados para o "respeito à diferença": como um valor, expressão da "liberdade", e como a igualdade possível.

Em que medida "o reconhecimento da especificidade das formas urbanas já criadas e consolidadas ao longo de décadas de ocupação informal” (Alfonsín \& Fernandes, 2004, p.2) fortalece o projeto de reconhecimento desses moradores como iguais, como sujeitos políticos com as mesmas condições de disputar recursos públicos? Formular, como pressuposto, a escassez dos recursos e o conjunto de impossibilidades daí decorrentes, coloca em risco o projeto democrático de cidade. As Zeis institucionalizam os "mínimos" de bem-estar produzidos pela espoliação urbana, legitimando esses parâmetros dentro e fora dos territórios regularizados. ${ }^{11}$ A legitimidade se sustenta na naturalização da escassez de recursos para investimento, reduzindo o campo de possibilidades a ser formulado pelos moradores. Como exemplo, podemos apontar a relação entre os novos "mínimos (a elevação da taxa de ocupação, a largura das vielas etc.) e a "impossibilidade" de transferência de parte dos domicílios para áreas próximas. Já vimos que essa impossibilidade poderia ser rompida por meio da utilização da própria Zeis em áreas vazias.

Por serem contraditórios, os processos aqui analisados carregam potencialidades de radicalização da democracia. Podemos pensar em novos padrões de urbanização e bemestar, instituídos nas Zeis por meio da participação popular, como "novos direitos" para todos, ou seja, novos mínimos para toda a cidade. ${ }^{12}$ Alfonsín \& Fernandes (2004, p.1) colocam em questão o conjunto de parâmetros urbanísticos que vigoram nas grandes cidades, e "que expressam uma tradição de planejamento urbano elitista e tecnocrático". Essa é uma problemática relevante, que precisa entrar na pauta da luta política. A politização das normas permite desvendar os interesses de classe presentes na legislação urbanística e fundiária. É inegável que a Lei para "todos” expressa interesses privatistas de alguns, mas é inegável também que ela é resultado de uma disputa material e simbólica sobre os parâmetros de bem-estar.

Do ponto de vista dos moradores das áreas regularizadas ou potencialmente regularizáveis, em que medida os parâmetros mínimos de bem-estar são internalizados como valor positivo ou como sinal de inferioridade? Segundo uma moradora da Comunidade Criança Esperança, em Bangu, ${ }^{13}$ o assentamento onde morava não era uma favela porque "favela é onde tem beco, casa colada uma na outra. Ninguém tem privacidade. Aqui, não. É proibido colar as casas". A clara distinção entre espaço público e privado, base do processo de individualização, começa a se fazer presente nas mentes das classes populares. A legitimidade e ampliação das ações coletivas direcionadas para a transformação profunda da sociedade estão associadas à constituição de indivíduos que se vêem como iguais.
11 Os critérios para a medição dos mínimos necessários para a reprodução social são arbitrários e valorativos e fazem parte da estrutura de valores de cada sociedade. Na luta política, os indivíduos reelaboram os valores instituídos, reproduzindo-os e transformando-os. Para aprofundar essa discussão, ver Nunes (1990).

12 A re-inclusão das vilas no zoneamento da cidade do Rio de Janeiro, poderia ter esse sentido.

13 Depoimento por mim recolhido, em 2003, no âmbito da pesquisa, ainda em curso, sobre segregação urbana na metrópole do Rio de Janeiro, Observatório das Metrópoles.

Luciana Corrêa do Lago é professora do Instituto de Pesquisa e Planejamento Urbano e Regional da Universidade Federal do Rio de Janeiro. E-mail: lucianalago @terra.com.br

Artigo recebido em dezembro de 2004 e aceito para publicação em fevereiro de 2005. 


\section{REFERÊNCIAS BIBLIOGRÁFICAS}

ALFONSÍN, B. M. Direito à moradia: instrumentos e experiências de regularização fundiária nas cidades brasileiras. FASE-GTZ-IPPUR/UFRJ-Observatório, 1997.

ALFONSÍN, B. M.; FERNANDES, E. Da igualdade e da diferença. Texto encaminhado para a Rede de Regularização: regularizacao@cidades.gov.br, 2004.

CASTEL, R. As metamorfoses da questão social. Uma crônica do salário. Rio de Janeiro: Vozes, 1998.

CHAUÍ, M. Considerações sobre a democracia e alguns dos obstáculos à sua concretização. Trabalho apresentado no Seminário "Os sentidos da Democracia e da Participação", ABONG e outros, São Paulo, julho de 2004.

DE SOTTO, H. O mistério do capital. Rio de Janeiro: Record, 2001.

DUARTE, L. F. et al. Vicissitudes e limites da conversão à cidadania nas classes populares brasileiras. RCBS, n.22, p.5-19, junho de 1993.

INSTITUTO PÓLIS (Coord.) Regularização da terra e da moradia: o que é e como implementar. 2002.

MINISTÉRIO DAS CIDADES. Planejamento territorial urbano e política fundiária. Brasília, Cadernos MCidades, n.3, 2004.

MIRANDA, L.; MORAES, D. "O Plano de Regularização das Zonas Especiais de Interesse Social (PREZEIS) do Recife: democratização da gestão e planejamento participativo". Pesquisa Rede Habitat: Rede Nacional da Avaliação e Disseminação de Experiências Alternativas em Habitação Popular. Relatório, 2003.

NUNES, E. "Carências urbanas e modos de vida". São Paulo em Perspectiva, v.4, n.2, p.2-7, 1990.

PIQUET, R. Cidade-empresa: presença na paisagem urbana brasileira. Rio de Janeiro: Jorge Zahar, 1998.

A B S T R A C T The essay searches to confront the project of citizenship, contained in the Urban Reform ideal, with the directions of the Brazilian urban policies, local and national, addressed for the enlargement of the access rights to the city. The analysis has as focus the regularization and urbanization policies in low income areas, based on the central place that occupies, today, the housing illegality in the formulation of the Brazilian urban question and public actions. So, the work is about an evaluation of the principles of the urban policies in course and not of their objective results. The main idea is that the legal instruments used in the poor areas, particularly the Zeis, load contradictory principles. It is questioned in what measure the legal norms and the specific urban patterns instituted in these territories institutionalize two classes of citizens, or two references of welfare, social right and property right; both legal and legitimate ones. One searches to contribute in the debate on the possibilities of "conviviality" between equality and difference, or even, between equality and freedom, in a deeply hierarchical and unequal society, where the difference is the expression of the inferiority of the poor classes.

K E Y W O R D S Citizenship; urban policy; housing. 